\title{
The effect of selective phosphodiesterase inhibitors, alone and in combination, on a murine model of allergic asthma Robert A Clayton* ${ }^{* 1}$, Colin AJ Dick ${ }^{\dagger 1}$, Alison Mackenzie ${ }^{1}$, Michiaki Nagasawa ${ }^{2}$, Deirdre Galbraith ${ }^{3}$, Stuart F Hastings ${ }^{1}$ and Simon J MacKenzie ${ }^{1}$
}

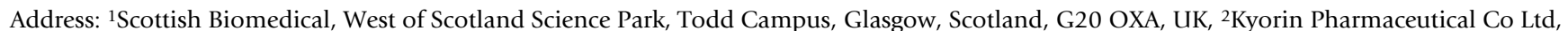
2399-1, Nogi, Nogi-machi, Shimotsuga-gun, Tokyo, Japan and 3Paisley University, Department of Biological Sciences, Paisley, Scotland, PA1 2BE, UK

Email: Robert A Clayton* - rob.clayton@Scottish-biomedical.com; Colin AJ Dick - colin.dick@scottish-biomedical.com; Alison Mackenzie - alison.mackenzie@scottish-biomedical.com; Michiaki Nagasawa - michiaki.nagasawa@mb.kyorin-pharm.co.jp; Deirdre Galbraith - galb-bs0@wpmail.paisley.ac.uk; Stuart F Hastings - stuart.hastings@scottish-biomedical.com; Simon J MacKenzie - simon.mackenzie@scottish-biomedical.com

* Corresponding author †Equal contributors

Published: 05 May 2004

Respiratory Research 2004, 5:4
Received: 19 December 2003

Accepted: 05 May 2004

This article is available from: http://respiratory-research.com/content/5/l/4

(c) 2004 Clayton et al; licensee BioMed Central Ltd. This is an Open Access article: verbatim copying and redistribution of this article are permitted in all media for any purpose, provided this notice is preserved along with the article's original URL.

\begin{abstract}
Background: The anti-inflammatory effects of the selective phosphodiesterase (PDE) inhibitors cilostazol (PDE 3), RO 20-I724 (PDE 4) and sildenafil (PDE 5) were examined in a murine model of allergic asthma. These compounds were used alone and in combination to determine any potential synergism, with dexamethasone included as a positive control.

Methods: Control and ovalbumin sensitised Balb/C mice were administered orally with each of the possible combinations of drugs at a dose of $3 \mathrm{mg} / \mathrm{Kg}$ for 10 days.

Results: When used alone, RO 20-1724 significantly reduced eosinophil influx into lungs and lowered tumour necrosis factor- $\alpha$, interleukin- 4 and interleukin- 5 levels in the bronchoalveolar lavage fluid when compared to untreated mice. Treatment with cilostazol or sildenafil did not significantly inhibit any markers of inflammation measured. Combining any of these PDE inhibitors produced no additive or synergistic effects. Indeed, the anti-inflammatory effects of RO 20-1724 were attenuated by co-administration of either cilostazol or sildenafil.
\end{abstract}

Conclusions: These results suggest that concurrent treatment with a PDE 3 and/or PDE 5 inhibitor will reduce the anti-inflammatory effectiveness of a PDE 4 inhibitor.

\section{Background}

The cyclic nucleotides, cAMP and cGMP are important second messengers known to control many cellular processes, such as inflammation. The cyclic nucleotide signalling system is both complex and interlinked with many other pathways [1], their signals being tightly controlled by regulating the synthesis and breakdown of these mole- cules. The only means the cell possesses to degrade the signal mediated by cyclic nucleotides is through the action of a large family of enzymes, the cyclic nucleotide phosphodiesterases [2].

To date, 11 PDE families have been identified. As these can be derived from multiple genes, many capable of 
generating a number of isoforms, there currently exists over 50 known PDE enzymes [3-6]. Differences in tissue expression patterns and spatial compartmentalisation within cells resulting in unique functional roles, and controlling mechanisms, is believed to explain the requirement for a large number of enzymes performing a similar process.

Their great diversity, and key role in controlling cyclic nucleotide signalling, makes the PDE family attractive drug targets. In recent years, a number of inhibitors of these enzymes have been brought to the market. Examples of these are the PDE 3 inhibitor, cilostazol, for the treatment of intermittent claudication [7], and sildenafil, a PDE 5 inhibitor, for the treatment of sexual dysfunction [8]. The PDE 4 family has also been extensively investigated, as inhibitors of these enzymes are known to be both potent anti-depressants and anti-inflammatory agents $[9,10]$. To date, side effects have prevented PDE4 inhibitors being used commercially, however, a number of groups now appear near to market with specific inhibitors for the treatment of airway diseases [11-13].

Extensive studies using specific inhibitors both in vitro and in vivo have demonstrated the regulation of airway smooth muscle by cAMP specific PDE 3 and PDE 4 families [14-16]. Members of both families are also expressed in cells of the immune system and considerable attention has been focussed on the potential of selective inhibitors of PDE 3 and PDE 4, or in combination, for the treatment of asthma and other inflammatory diseases [17-21]. In contrast, despite the presence of the cGMP hydrolysing PDE 5 in airways, the potential anti-inflammatory actions of selective inhibitors has not been fully investigated.

It has been reported that not only do PDE 3 and PDE 4 inhibitors induce relaxation of airways [22], a combined inhibition of both may produce a more potent antiinflammatory effect than single inhibition of either alone [23]. In human alveolar macrophages, endotoxin-induced release of TNF- $\alpha$ is only completely inhibited by a combination of the PDE 3 inhibitor, motapizone, and the PDE 4 inhibitor, rolipram [24]. In passively sensitised human airways, allergen-induced contraction was inhibited only by the simultaneous inhibition of PDE 3 and PDE 4 and not by single inhibition of either family [25]. Furthermore, ovalbumin-induced pulmonary eosinophil influx in guinea pigs was attenuated more effectively by a mixed PDE 3/4 inhibitor than by either a selective PDE 3 or PDE 4 inhibitor $[23,26]$. Whether this synergistic relationship is unique to PDE 3 and PDE 4 alone, or if combinations of other PDE inhibitors will produce similar increases in anti-inflammatory activity, remains to be seen. Interestingly, in an in vivo model of pulmonary resistance, the PDE 3 inhibitor, milrinone, and the PDE 5 inhibitor, zap- rinast offer a synergistic effect when used in combination [27]. To date, however, very little is known regarding the potential interaction between selective inhibitors of PDE 3, PDE 4 and PDE 5.

With PDE inhibitors becoming more commonly used to treat disease, our study sought to determine the effects that combinations of inhibitors may have upon the antiinflammatory effects of a PDE 4 inhibitor. Therefore, we investigated the abilities of a PDE 3 selective inhibitor (cilostazol), a PDE 4 selective inhibitor (RO 20-1724) and a PDE 5 selective inhibitor (sildenafil), to inhibit inflammation in a murine model of allergic asthma [28]. The effectiveness of these drugs was evaluated when administered alone and in combination. These results suggest that co-administration of a PDE 3 and/or PDE 5 inhibitor may reduce the anti-inflammatory effectiveness of a PDE 4 inhibitor.

\section{Methods \\ Animals}

Male Balb/c mice, 6 weeks old on arrival and weighing 20-25 g, were obtained from B\&K Universal. The mice were housed for 10 days prior to the beginning of the study. The mice were provided with standard laboratory chow and tap water ad libitum. Animals were maintained on a 12-h light/dark cycle at appropriate humidity and temperature levels. Protocols used in this study were approved by the appropriate ethical committees. The animals used in this study were placed into 2 experimental blocks of 40 mice, staggered 1 day apart. Each experimental block consisted of all groups ( 4 mice/group) with both data sets merged at the end of the study. To avoid experimental bias mice were sacrificed, 1 animal per group, until all groups had been processed and then repeated 4 times.

\section{Allergen sensitisation, challenge and dosing}

Mice were sensitised by the administration of two intraperitoneal injections, twelve days apart (Day 0 and 12), of $50 \mu \mathrm{g}$ of ovalbumin (OVA; Grade V, Sigma) with $1 \mathrm{mg}$ of Aluminium hydroxide in $0.5 \mathrm{ml}$ sterile saline $(0.9 \%$ sodium chloride). Ten, fourteen and eighteen days after the last immunisation (Days 22, 26 and 30), mice were challenged for 30 minutes with an aerosol of ovalbumin generated from a $1 \%$ solution (wt/v) of ovalbumin in sterile saline using an ultrasonic nebulizer. Control animals were challenged with aerosolised sterile saline only. The inhibitors cilostazol (PDE 3), RO 20-1724 (PDE 4) and sildenafil (PDE 5) were dissolved in sterile saline solution containing $0.1 \%(\mathrm{v} / \mathrm{v})$ Tween 20 (Sigma) and administered alone or in combination (Table 1 ). The glucocorticoid, dexamethasone-21-phosphate, di-sodium salt (Sigma) was also dissolved in sterile saline solution containing $0.1 \%(\mathrm{v} / \mathrm{v})$ Tween 20 . Drugs were administered by 
Table I: Drug treatment for experimental study groups

\begin{tabular}{ccc}
\hline Study Group & Drug & PDE Inhibition \\
\hline A & Saline & - \\
B & Saline & - \\
C & Cilostazol & 3 \\
D & RO 20-I724 & 4 \\
E & Sildenafil & 5 \\
F & Cilostazol + RO 20-1724 & $3+4$ \\
G & Cilostazol + Sildenafil & $3+5$ \\
H & RO 20-1724 + Sildenafil & $4+5$ \\
I & Cilostazol + RO 20-I724 + Sildenafil & $3+4+5$ \\
J & Dexamethasone & - \\
\hline
\end{tabular}

Table 2: Inhibitory potency $(\mu \mathrm{M})$ of study compounds against cloned human PDE's. Measurements were determined by a modification of the 2 step procedure described by Thompson and Applegate (197I).

\begin{tabular}{cccc}
\hline & PDE 3 $\left(\mathrm{IC}_{50}\right)$ & PDE 4 $\left(\mathrm{IC}_{50}\right)$ & PDE 5 (IC $\left.{ }_{50}\right)$ \\
\hline Cilostazol & 3.7 & $>100$ & $\mathrm{Nil}$ \\
Ro 20-1724 & $\mathrm{Nil}$ & 1.3 & $\mathrm{Nil}$ \\
Sildenafil & $\mathrm{Nil}$ & $\mathrm{Nil}$ & 0.061 \\
\hline
\end{tabular}

oral gavage daily for the final ten days of the sensitisation protocol (Days 20-30). All drugs were administered to give a final dose of $3 \mathrm{mg} / \mathrm{Kg}$ body weight, an effective, common dose used in similar studies.

\section{Bronchoalveolar lavage and serum collection}

Twenty-four hours after the last ovalbumin challenge, mice were sacrificed with an overdose of sodium pentabarbitone (Rhone Meroux). Blood was obtained by cardiac puncture prior to bronchoalveolar lavage being performed. The collected blood was centrifuged at 13,225 $\mathrm{g}$ for $10 \mathrm{~min}$ before the serum was collected and stored at $-80^{\circ} \mathrm{C}$. Mice were then lavaged by cannulating the trachea and instilling $1.0 \mathrm{ml}$ of sterile saline, twice with the same solution. The lavage was repeated with a second $1.0 \mathrm{ml}$ of sterile saline. The lavage fluid was then centrifuged at 400 $\mathrm{g}$ for $10 \mathrm{~min}$ at $4^{\circ} \mathrm{C}$. The supernatant from the first lavage was stored at $-80^{\circ} \mathrm{C}$ for subsequent biological analysis. The cell pellets from both lavages were combined and resuspended in $0.5 \mathrm{ml}$ RPMI 1640 media (Sigma) supplemented with 5\% Foetal Calf Serum (PAA Laboratories). The cell suspension (10 ul) was mixed with Turk's solution (Gift from Kyorin Pharmaceutical Co Ltd) in a 1:1 ratio before the total cell number was then calculated by way of haemocytometer. Cytospin preparations of the bronchoalveolar lavage (BAL) cells were prepared in duplicate for each sample (Cytospin 3; Shandon). The slides were then fixed and stained with Quick Stain (Ray- mond Lamb) to allow differentiation between cell types. Differential counts were based on at least 200 cells per slide, using standard morphologic criteria to identify cells as monocytes, eosinophils or neutrophils.

\section{Serum IgE assay}

Serum IgE was determined using an ELISA kit purchased from BD biosciences (Kit No - 555248).

\section{Measurement of inflammatory cytokines}

Levels of TNF- $\alpha$, IL- 4 and IL-5 in BAL fluid were determined using a Bioplex protein array system (Biorad) with matched antibody pairs for murine TNF- $\alpha$, IL-4 and IL-5.

\section{Measurement of phosphodiesterase activity}

PDE activity was determined by a modification of the 2step procedure by Thompson and Applegate, 1971 [29] adapted to a 96 well plate format.

\section{Statistical analysis}

Groups were analysed using one-way analysis of variance with Dunnett's Multiple Comparison Test (GraphPad Prism). Differences were considered significant if $\mathrm{p}<0.05$. Values for all measurements are expressed as mean \pm SEM. 

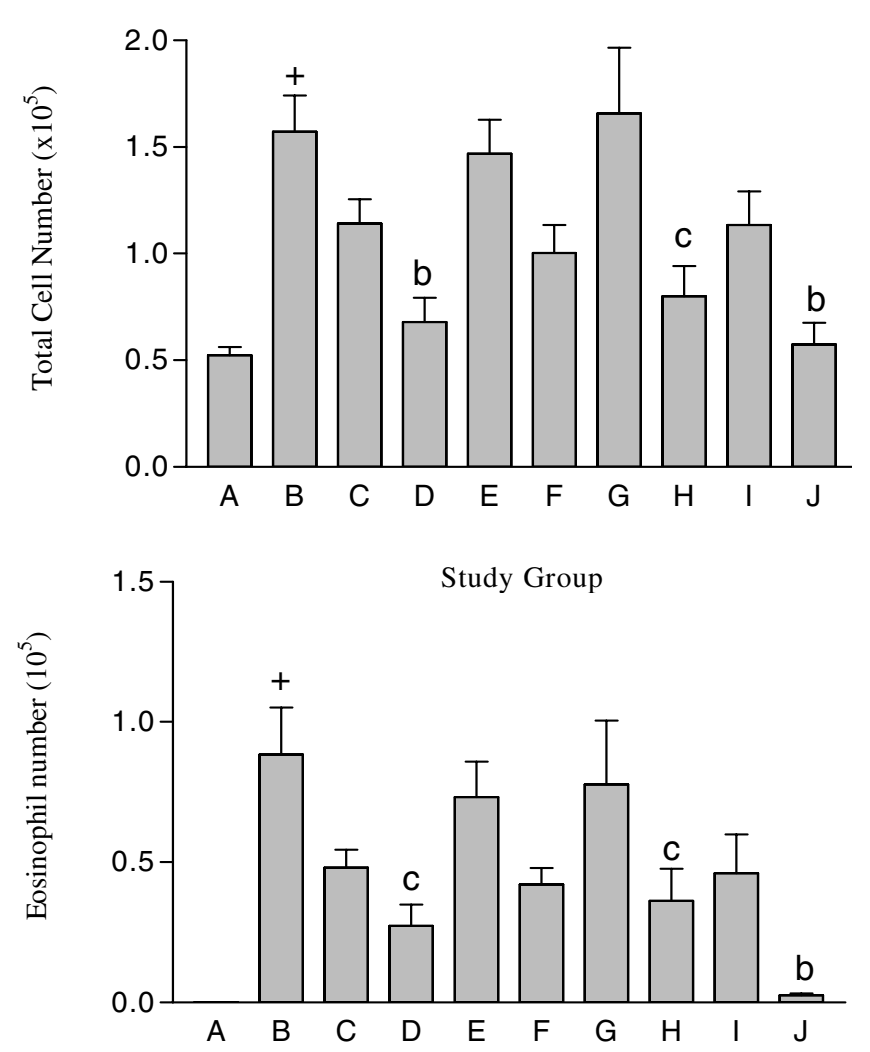

Study Group

\section{Figure I}

Total leukocyte $(A)$ and eosinophil $(B)$ numbers in $B A L$ fluid recovered from male Balb/c mice following drug treatment. Group A was non-OVA challenged mice orally injected with saline. Groups B to J were OVA challenged mice orally injected with either saline (Group B) or PDE compound (3 $\mathrm{mg} / \mathrm{kg}$ ). Group C received cilostazol. Group D received RO 20-I724. Group E received sildenafil. Group F received cilostazol + RO 20-1724. Group G received cilostazol + sildenafil. Group H received RO 20-I724 + sildenafil. Group I received cilostazol + RO 20-I724 + sildenafil. Group J received Dexamethasone. Each study group contained $n=8$ mice. $+p<0.001$ compared to non OVA challenged mice (Group A), b p < 0.0I compared to OVA challenged mice orally gavaged with saline, $c p<0.05$ compared to OVA challenged mice orally gavaged with saline

\section{Results}

\section{Cellular analysis of BAL fluid}

Total leukocyte numbers

Total leukocyte numbers were significantly ( $\mathrm{p}<0.001$ ) increased in OVA-challenged mice compared to non-OVA challenged mice (Group A; Figure 1A, Table 3) and markedly inhibited by Dexamethasone $(\mathrm{p}<0.01)$.
When used alone, only RO 20-1724 (Group D) significantly ( $p<0.01$ ) reduced the leukocyte count compared with OVA sensitised mice. Treatment with either cilostazol (Group C) or sildenafil (Group E) alone did not alter the number of leukocytes in the BAL fluid.

When used in combination, only a pairing of RO 20-1724 and sildenafil (Group H) significantly $(\mathrm{p}<0.05)$ reduced the total leukocyte count compared to OVA sensitised mice. Combining RO 20-1724 with sildenafil, or cilostazol (Group F), however, produced no significantly different response than when RO 20-1724 was used alone. No additive or synergistic effects were seen with cilostazol and RO 20-1724 (Group F), or with cilostazol and sildenafil (Group G). The combination of all three PDE inhibitors (Group I), did not significantly reduce the leukocyte count compared to OVA sensitised mice.

\section{Differential cell counts}

The cells in the BAL fluid from non-OVA challenged mice were almost exclusively monocytes, with little or no eosinophils present (Figure 1B, Table 3). In OVA-challenged mice receiving an oral instillation of saline (Group $\mathrm{B}$ ), eosinophils comprised $53.7 \pm 8.8 \%$ of the total cell number and was highly significantly $(\mathrm{p}<0.001)$ compared to control animals. Treatment with dexamethasone (Group J) ameliorated the number of eosinophils in the BAL fluid ( $4.0 \pm 0.9 \%$ of total cell number).

Alone, only RO 20-1724 (Group D; $30.7 \pm 3.7 \%$ ) significantly $(\mathrm{p}<0.05)$ reduced the number of eosinophils in the BAL compared to OVA sensitised mice. Treatment with either cilostazol $(42.5 \pm 4.3 \%)$ or sildenafil $(48.9 \pm$ $4.9 \%$ ) alone did not reduce the number of influxing eosinophils. As was the case for total leukocyte number only a combination of RO 20-1724 and sildenafil significantly $(p<0.05)$ reduced the number of eosinophils in the BAL compared to OVA sensitised mice.

\section{Cytokine analysis of BAL fluid}

Tumour necrosis factor- $\alpha$ measurement

Levels of TNF- $\alpha$ were significantly $(\mathrm{p}<0.05)$ higher in OVA challenged mice (Group B) compared to non-OVAchallenged mice (Figure 2A, Table 4) and mice receiving Dexamethasone. Treatment with either cilostazol (Group C) or sildenafil (Group E) alone did not alter TNF- $\alpha$ levels in the BAL fluid. In contrast, RO 20-1724 alone (Group D) significantly $(\mathrm{p}<0.05)$ reduced the TNF- $\alpha$ levels compared to OVA sensitised mice. Study groups receiving the combination of PDE inhibitors exhibited no additive or synergistic effects compared to each PDE inhibitor used on its own in altering TNF- $\alpha$ levels compared to OVA sensitised mice. In all combinations, the effect of the PDE 4 inhibitor is lost. 
Table 3: Total leukocyte and differential cell numbers in BAL fluid recovered from male Balb/c mice following drug treatment ( $\left.\times 10^{3}\right)$. Each study group contained $\mathbf{n}=\mathbf{8}$ mice.

\begin{tabular}{ccccc}
\hline Study Group & Total & Monocytes & Neutrophil & Eosinophil \\
\hline A & $52.50 \pm 3.70$ & $52.5 \pm 3.6$ & $0.0 \pm 0.0$ & $0.0 \pm 0.0$ \\
B & $157.20 \pm 16.80 \mathbf{a}$ & $77.2 \pm 17.9$ & $0.1 \pm 0.1$ & $88.5 \pm 16.7 \mathbf{a}$ \\
C & $114.10 \pm 11.50$ & $65.6 \pm 8.2$ & $0.1 \pm 0.1$ & $48.1 \pm 6.4$ \\
D & $67.90 \pm 11.40 \mathbf{b}$ & $52.0 \pm 8.4$ & $0.0 \pm 0.0$ & $27.3 \pm 7.6 \mathbf{c}$ \\
E & $146.90 \pm 15.90$ & $73.7 \pm 10.0$ & $0.0 \pm 0.0$ & $73.1 \pm 12.8$ \\
F & $100.30 \pm 13.20$ & $58.3 \pm 9.5$ & $0.0 \pm 0.0$ & $42.1 \pm 5.9$ \\
G & $165.80 \pm 30.80$ & $88.1 \pm 15.2$ & $0.0 \pm 0.0$ & $77.7 \pm 22.7$ \\
H & $79.90 \pm 14.30 \mathbf{c}$ & $43.8 \pm 6.1$ & $0.0 \pm 0.0$ & $36.1 \pm 11.5 \mathbf{c}$ \\
I & $113.40 \pm 15.90$ & $67.3 \pm 12.4$ & $0.0 \pm 0.0$ & $46.0 \pm 13.8$ \\
J & $57.50 \pm 10.10 \mathbf{b}$ & $55.1 \pm 9.5$ & $0.0 \pm 0.0$ & $2.5 \pm 0.7 \mathbf{b}$ \\
\hline
\end{tabular}

a $p<0.001$ compared to non OVA challenged mice (Group A), $\mathbf{b} p<0.01$ compared to OVA challenged mice orally gavaged with saline (Group $B$ ), c $p<0.05$ compared to OVA challenged mice orally gavaged with saline (Group B)

\section{Interleukin-4 measurement}

Levels of IL- 4 were significantly $(\mathrm{p}<0.05)$ higher in OVA challenged mice compared to the non-OVA-challenged mice (Figure 2B, Table 4 ) and mice receiving dexamethasone. The administration of either cilostazol (Group C) or sildenafil (Group E) alone did not alter IL-4 levels in BAL fluid. In contrast, RO 20-1724 alone (Group D) significantly $(\mathrm{p}<0.05)$ reduced the IL-4 levels compared to OVA sensitised mice. Combining selective PDE inhibitors exhibited no additive or synergistic effects compared to each PDE inhibitor used on its own, and in fact reduced the effect of RO 20-1724 on its own.

\section{Interleukin-5 measurement}

Levels of IL-5 were significantly $(\mathrm{p}<0.05)$ higher in OVA challenged mice compared to the non-OVA-challenged mice (Figure 2C, Table 4) and in mice receiving Dexamethasone. When either cilostazol (Group C) or sildenafil (Group E) was used alone, this did not alter IL-5 levels in the retrieved BAL fluid. In contrast to this RO 20-1724 (Group D) alone significantly ( $\mathrm{p}<0.05$ ) reduced the amount of IL- 5 compared to controls. Again as is observed with IL-4 and TNF- $\alpha$ the combining of PDE inhibitors resulted in no additive effects in the reduction of IL-5, and reduced the effects of the PDE 4 inhibitor on its own.

\section{Serum IgE}

Total serum IgE was significantly increased by ovalbumin sensitisation and challenge in comparison with non-ovalbumin challenged mice and was not altered by any of the combinations of compounds, with the exception of dexamethasone (data not shown).

\section{Discussion}

The benefits of inhibiting PDEs in disease has been known for many years, however, only recently have drugs emerged that lack the side effects normally associated with these drugs [11]. Several new PDE 4 inhibitors, possessing little side effects, are nearing launch. In our study, we wished to determine whether there was any synergy in anti-inflammatory function when PDE inhibitors were used in combination. An enhancing effect with one of these combinations, compared to the effects of a PDE 4 inhibitor alone, could suggest this as a possible preferential treatment for inflammatory conditions. A synergistic effect could result in the administration of lower doses of inhibitor, lowering any potential side effects.

A range of PDE inhibitors are about to be launched, or are already in use. Cilostazol, a PDE 3 inhibitor, is being used to treat circulatory problems [7]. Sildenafil, a PDE 5 inhibitor is used for the treatment of sexual dysfunction and may potentially be used in cardiovascular disease [30], and there is the imminent release of new PDE 4 inhibitors for inflammatory lung disease $[11,31]$. Due to the success of these PDE inhibitors in the treatment of varied diseases, in future years there exists the potential for a patient to be taking a combination of drugs that will inhibit more than one PDE family.

The results from this study demonstrate that the PDE 4 inhibitor, RO 20-1724, exhibits potent anti-inflammatory actions in our murine model of allergic asthma. Neither the PDE 3 inhibitor, cilostazol, nor the PDE 5 inhibitor, sildenafil, produced any significant anti-inflammatory effect. This conflicts with a recent study that indicated potential benefits of sildenafil in an OVA model [32]. However, their model used different animals and the administration of the drug was by peritoneal injection, not oral. In addition, the significant anti-inflammatory effects of the PDE 4 inhibitor are reduced upon co-administration with the PDE 3. This is in contrast to many studies that show that a combined PDE3/4 inhibitor has better efficacy over a separate PDE 3 or 4 inhibitor. Our study 

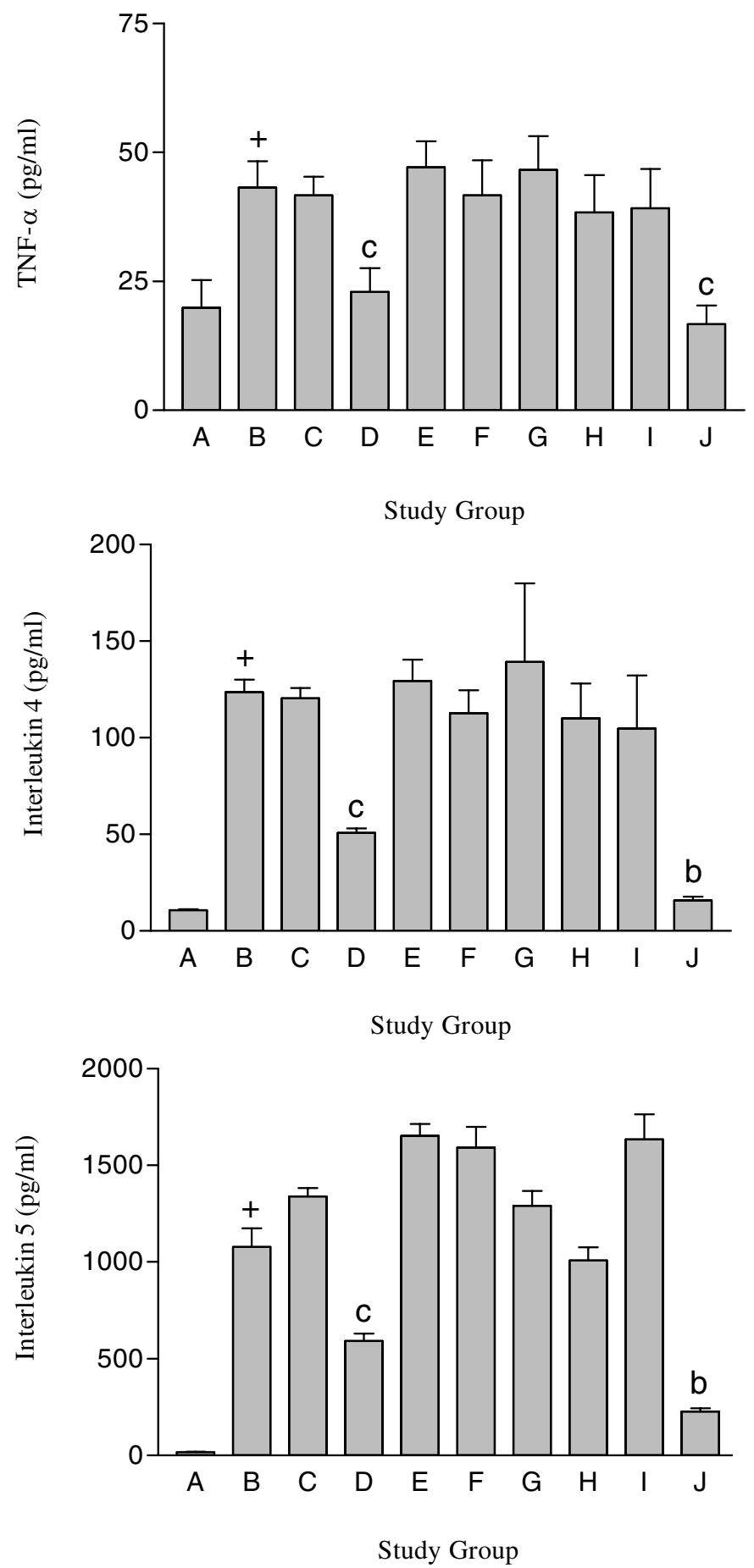

Figure 2

TNF- $\alpha$ (A), IL-4 (B) and IL-5 (C) concentrations in BAL fluid recovered from male Balb/c mice following drug treatment. Group A was non-OVA challenged mice orally injected with saline. Groups B to J were OVA challenged mice orally injected with either saline (Group B) or PDE compound (3 mg/kg). Group C received cilostazol. Group D received RO 20-I724. Group E received sildenafil. Group F received cilostazol + RO 20-I 724. Group G received cilostazol + sildenafil. Group H received RO 20-I724 + sildenafil. Group I received cilostazol + RO 20-I724 + sildenafil. Group J received Dexamethasone. Each study group contained $n=8$ mice. $+p<0.00$ I compared to non OVA challenged mice (Group A), b $p<0.0$ I compared to OVA challenged mice orally gavaged with saline, $c p<0.05$ compared to OVA challenged mice orally gavaged with saline 
Table 4: TNF- $\alpha$ (A), IL-4 (B) and IL-5 (C) concentrations in BAL fluid recovered from male Balb/c mice following drug treatment. Cytokine concentrations were measured using a Biolplex ELISA system. Each study group contained $\mathbf{n}=8 \mathrm{mice}$.

\begin{tabular}{|c|c|c|c|}
\hline \multirow[b]{2}{*}{ Study Group } & \multicolumn{3}{|c|}{ Concentration in BAL fluid $(\mathrm{pg} / \mathrm{ml})$} \\
\hline & TNF $\alpha$ & $\mathrm{IL}-4$ & IL-5 \\
\hline$A$ & $19.9 \pm 5.3$ & $10.7 \pm 0.5$ & $18.2 \pm 0.58$ \\
\hline B & $43.2 \pm 5.1$ a & $123.6 \pm 66.3 \mathrm{a}$ & $1077.1 \pm 273.5 \mathrm{a}$ \\
\hline C & $41.6 \pm 3.6$ & $120.3 \pm 5.3$ & $1339.7 \pm 120.5$ \\
\hline $\mathrm{D}$ & $22.9 \pm 4.6 \mathrm{c}$ & $50.7 \pm 2.4 c$ & $591.9 \pm 108.2 \mathrm{c}$ \\
\hline $\mathrm{E}$ & $47.1 \pm 5.0$ & $129.4 \pm 11.0$ & $1652.9 \pm 174.1$ \\
\hline $\mathrm{F}$ & $41.6 \pm 6.8$ & $112.8 \pm 11.9$ & $1592.5 \pm 30 \mid .4$ \\
\hline G & $46.5 \pm 6.5$ & $139.3 \pm 40.7$ & $1290.3 \pm 218.4$ \\
\hline $\mathrm{H}$ & $38.3 \pm 7.2$ & $110.1 \pm 18.0$ & $1007.6 \pm 194.5$ \\
\hline I & $39.1 \pm 7.6$ & $104.8 \pm 27.5$ & $1634.9 \pm 367.7$ \\
\hline$J$ & $16.7 \pm 3.6 \mathrm{c}$ & $15.8 \pm 2.1 \mathbf{b}$ & $227.9 \pm 45.0$ b \\
\hline
\end{tabular}

a $p<0.001$ compared to non OVA challenged mice (Group A), $\mathbf{b} p<0.01$ compared to OVA challenged mice orally gavaged with saline (Group $B$ ), $c p<0.05$ compared to OVA challenged mice orally gavaged with saline (Group B)

used a combination of separate PDE 3 and PDE 4 inhibitor and not a dual/mixed compound which posses both PDE 3 and PDE 4 inhibitory potential.

The anti-inflammatory actions of PDE 4 inhibitors are well documented both in vitro and in vivo. Selective inhibition of PDE 4 suppresses several eosinophil functions such as superoxide anion generation [33], adhesion and migration [34]. Furthermore, PDE 4 inhibitors produce marked anti-inflammatory actions in several animal models of allergic asthma [21,22,35].

Glucocorticoids, such as dexamethasone, are often used as positive control drugs in models of allergic asthma [36]. Dexamethasone inhibits leukocyte migration into sites of inflammation, predominantly by inhibiting the synthesis of pro-inflammatory cytokines and chemokines [24]. In this present study, the effects of RO 20-1724 on leukocyte infiltration and pro-inflammatory cytokine levels approached those of dexamethasone, emphasising the potency of PDE 4 inhibitors as anti-inflammatory agents. In our study dexamethasone is able to significantly reduce cell number (total and eosinophil) and inflammatory mediators (IL-5, IL-4 and TNF- $\alpha$ ) better or as good as the PDE 4 inhibitor used in the study. Long term, high doses of steroids should be avoided and it may be possible to use PDE4 drugs in combination with lower doses of steroids. We would propose further study into the effects of combining PDE 4 compounds and steroids.

All of the parameters of inflammation that were measured exhibited very similar trends. Thus, the overall pattern of results for cellular infiltration and the levels of the proinflammatory cytokines, IL-4, IL-5 and TNF- $\alpha$, in the BAL fluid were remarkably similar. The Th2-derived cytokines,
IL-4 and IL-5 play a central role in initiating and sustaining an asthmatic response by regulating the production of IgE as well as the growth, differentiation and recruitment of inflammatory cells [37]. Indeed, a positive correlation between lung eosinophilia and levels of IL-4 and IL-5 in BAL fluid has previously been reported, both in humans [38] as well as animal models of allergic asthma [39]. Levels of TNF- $\alpha$ are also increased in the airways and BAL fluid of asthmatics relative to healthy subjects $[38,40]$, indicating a possible involvement of this pro-inflammatory cytokine in the development of asthma.

Our results are in keeping with previous studies reporting that PDE 4 inhibitors suppress levels of these cytokines. Rolipram inhibits TNF- $\alpha$ production from LPS-stimulated monocytes in vitro [41,42] and from mice in vivo [43]. Furthermore, the second-generation PDE 4 inhibitors, Ariflo (SB 207499) and Roflumilast both attenuate TNF- $\alpha$ levels in the BAL fluid from rats and guinea pigs [31] and inhibit TNF- $\alpha$, IL-4 and IL-5 production in vitro [44].

In some model systems PDE 3 inhibitors have shown the ability to reduce selected markers of inflammation either in vitro or in vivo. Cilostazol has been shown to attenuate superoxide anion release from guinea pig alveolar macrophages [45], while CI-930 was able to decrease eosinophil influx to a similar extent as rolipram in a Brown Norway rat model of asthma [22]. However, many groups have shown that PDE 3 inhibitors offer no anti-inflammatory potential in vivo, such as siguazodan [37], SK\&F 94120 [27] and SK\&F 94836 [13]. Possibly, variation in the models used and inhibition profiles of the these compounds accounts for these observed differences. 
Although the anti-inflammatory actions of PDE 5 inhibitors have not been as widely studied as those of PDE 3 or PDE 4 inhibitors, most studies have shown PDE 5 inhibitors to have little or no effect at reversing inflammation, although recent reports may suggest otherwise [32]. In a recent study, zaprinast failed to inhibit superoxide anion release from guinea pig alveolar macrophages $[16,45]$. Furthermore, rolipram, but not zaprinast, reduced eosinophil recruitment into the lungs in sensitised rats [22,46] and guinea pigs [37].

In this present series of experiments, we have used sildenafil as the inhibitor of cGMP specific PDE 5. Sildenafil is reported to be more selective for PDE 5 than zaprinast and several times more potent, with a low nanomolar $\mathrm{IC}_{50}$ (12). Despite its high selectivity and potency for PDE 5, sildenafil, when used alone, produced no reduction in inflammation in our experiments. These findings are in agreement with the general consensus in that PDE 4 inhibitors are potent anti-inflammatory agents, whereas PDE 3 and PDE 5 inhibitors have little or no effect.

A major aspect of this study was to examine the possible interaction between inhibitors of the PDE 3, PDE 4 or PDE 5 families. More specifically, to examine if a combination of a PDE 3, PDE 4 or PDE 5 inhibitor produced any additive or synergistic benefit as opposed to being used alone. A drawback with the administration of many PDE 4 selective inhibitors in the treatment of asthma is their considerable side effects, such as nausea and stomach acid secretion. Any synergistic or additive effect between a PDE 4 inhibitor and an inhibitor of PDE 3 or PDE 5, may allow lower doses of drug to be administered and thus reduce the severity of any side effects. However, we were unable to demonstrate any enhancement of RO 20-1724-mediated anti-inflammation with either cilostazol, sildenafil or indeed a combination of all three. In contrast, we observed that combining cilostazol with RO 20-1724 resulted in a decrease of the anti-inflammatory actions of the PDE 4 inhibitor. This may be due to a number of reasons such as alterations in PDE4 absorption across the gastrointestinal tract in the presence of PDE3 or PDE5 inhibitor or changes in intracellular signalling pathways.

\section{Conclusions}

The PDE 4 inhibitor, RO 20-1724, exhibited potent antiinflammatory actions in vivo, whereas the PDE 3 inhibitor, cilostazol, and the PDE 5 inhibitor, sildenafil, did not. Instead of observing synergy between PDE 3, PDE 4 and PDE 5, we observed a loss in the ability of the PDE 4 inhibitor to reduce inflammation in a murine model of allergic asthma. This finding has potential implications for patients who may use a combination of PDE inhibitors for a number of different conditions and maybe due in part to drug-drug interactions. This would not, however, be expected to occur with a single drug that contains combined inhibition of PDE 3 and 4 . Further research will be required to determine the cause of these interactions between the compounds.

\section{Authors' contributions}

RAC and CAJD carried out the allergic model, writing and preparation of the manuscript and subsequent biochemical analysis. AM carried out the allergic model and assisted with the writing and preparation of the manuscript and subsequent biochemical analysis. MN assisted with the writing and preparation of the manuscript. DG assisted with the allergic model. SFH and SJM participated in the direction of the study as well as writing and preparing the manuscript.

\section{References}

I. Houslay MD, Milligan G: Tailoring cAMP-signalling responses through isoform multiplicity. Trends Biochem Sci 1997, 22:217-224.

2. Houslay MD: Adaption in cAMP signalling processes: a central role in cyclic AMP phosphodiesterases. Sem Cell Dev Biol 1998, 9:161-167.

3. Beavo JA: Cyclic nucleotide phosphodiesterase: functional implications of multiple isoforms. Physiol Rev 1995, 75:725-748.

4. Bolger GB: Molecular biology of the cyclic AMP-specific cyclic nucleotide phosphodiesterases: a diverse family of regulatory enzymes. Cell Signal 1994, 6:851-859.

5. Loughney K, Ferguson K: Identification and quantification of PDE isoenzymes and subtypes by molecular biological methods. In Phosphodiesterase inhibitors Edited by: Schudt C, Dent G, Rabe KF. London: Academic Press; 1996: I- 19.

6. Soderling SH, Bayuga SJ, Beavo JA: Identification and characterisation of a novel family of cyclic nucleotide phosphodiesterases. J Biol Chem I998, 273: I5553-I5558.

7. Schror K: The pharmacology of Cilostazol. Diabetes Obes Metab 2002, 4:SI4-19.

8. Corbin JD, Francis SH, Webb DJ: Phosphodiesterase type 5 as a pharmacologic target in erectile dysfunction. Urology 2002, 60:4-11.

9. Barnette MS: Phosphodiesterase 4 (PDE4) inhibitors in asthma and chronic obstructive pulmonary disease (COPD). Prog Drug Res 1999, 53:193-229.

10. Souness JE, Aldous D, Sargent C: Immunosuppressive and antiinflammatory effects of cyclic AMP phosphodiesterase (PDE) type 4 inhibitors. Immunopharmacol 2000, 47:I27-I62.

II. Giembycz MA: Development status of second generation PDE4 inhibitors for asthma and COPD: the story so far. Monaldi Arch Chest Dis 2002, 57:48-64.

12. Houslay MD: PDE4 cAMP-specific phosphodiesterases. Prog Nucleic Acid Res Mol Biol 200 I, 69:249-3 I5.

13. Schudt $C$, Tenor $H$, Hatzelmann A: PDE isoenzymes as targets for anti-asthma drugs. Eur Respir J 1995, 8: I I79-I I83.

14. Harris AL, Connel MJ, Ferguson EW, Wallace AM, Gordon RJ, Pagani ED, Silver P: Role of low $\mathbf{K}_{\mathbf{m}}$ cyclic AMP phosphodiesterase inhibition in tracheal relaxation and bronchodilation in the guinea pig. J Pharmacol Exp Ther 1989, 25 I: | 99-206.

15. Heaslip RJ, Buckley SK, Sickels BD, Grimes D: Bronchial vs cardiovascular activities of selective phosphodiesterase inhibitors in the anaesthetized beta-blocked dog. J Pharmacol Exp Ther |99|, 257:74|-7.

16. Miyamoto K, Kurita M, Sakai R, Sanae F, Wakusawa S, Takagi K: Cyclic nucleotide phosphodiesterase isoenzymes in guinea pig tracheal muscle and bronchorelaxation by alkylxanthines. Biochem Pharmacol 1994, 48: I219-1223.

17. Banner $\mathrm{KH}$, Page $\mathrm{CP}$ : Immunomodulatory actions of xanthines and isoenzyme selective phosphodiesterase inhibitors. Monaldi Arch Chest Dis 1995, 50:286-292. 
18. Giembycz MA, Dent G: Prospects for selective nucleotide phosphodiesterase inhibitors in the treatment of bronchial asthma. Clin Exp Allergy 1992, 22:337-344.

19. Giembycz MA, Dent G, Souness JE: Theophyline and isoenzyme selective phosphodiesterase inhibitors. In: Allergy \& Allergic diseases Edited by: Kay AB. London: Blackwell Scientific; | 997:53|-567.

20. Torphy TJ: Molecular targets for the novel anti-asthma agents. Am J Respir Crit Care Med 1998, I 57:35 I-370.

21. Torphy TJ, Undem BJ: Phosphodiesterase inhibitors: new opportunities for the treatment of asthma. Thorax 1991, 46:512-523

22. Howell RE, Jenkins LP, Fielding LE, Grimes D: Inhibition of antigeninduced pulmonary eosinophilia and neutrophilia by selective inhibitors of phosphodiesterase types 3 or 4 in Brown Norway rats. Pulm Pharmacol 1995, 8:83-89.

23. Underwood DC, Kotzer C], Bochniwicz S, Osborn RR, Luttmann MA, Hay DWP, Torphy TJ: Comparison of phosphodiesterase III, IV and dual III/IV inhibitors on bronchospasm and pulmonary eosinophil influx in guinea pig. J Pharmacol Exp Ther 1994, 270:250-259.

24. Schleimer RP: Effects of glucocorticoids on inflammatory cells relevant to their therapeutic applications in asthma. Am $\mathrm{Rev}$ Respir Dis 1990, I41:S59-S69.

25. Schmidt DT, Watson N, Dent G, Ruhlmann E, Branscheid D, Magnussen $H$, Rabe KF: The effect of selective and non selective phosphodiesterase inhibitors on allergen- and leukotriene C4induced contractions in passively sensitised human airways. Br J Pharmacol 2000, I3 I:1607-1618.

26. Santing RE, de Boer J, Rohof A, van der Zee NM, Zaagsma J: Bronchodilatory and anti-inflammatory properties of inhaled selective phosphodiesterase inhibitors in a guinea pig model of allergic asthma. Eur J Pharmacol 2001, 429:335-44.

27. Teixeira MM, Rossi AG, Williams TJ, Hellewell PG: Effects of phosphodiesterase isoenzyme inhibitors on cutaneous inflammation in the guinea pig. Br J Pharmacol 1994, I I 2:332-340.

28. Kung TT, Jones H, Adams GK, Umland SP, Kreutner W, Egan Chapman RW, Watnick AS: Characterisation of a murine model of allergic pulmonary inflammation. Int Arch Allergy Immunol 1994, 1 05:83-90.

29. Thompson WJ, Appleman MM: Multiple cyclic nucleotide Phosphodiesterase activities from rat brain. Biochem 1971, 10:311-316.

30. Corbin JD, Francis SH: Pharmacology of phosphodiesterase-5 inhibitors. Int I Clin Pract 2002, 56:453-459.

31. Bundschuh DS, Eltze M, Barsig J, Wollin L, Hatzelmann A, Beume R: In vivo efficacy in airway disease models of roflumilast, a novel orally active PDE4 inhibitor. J Pharmacol Exp Ther 200I, 297:280-290.

32. Toward TJ, Smith N, Broadley KJ: Effect of Phosphodiesterase-5 Inhibitor, Sildenafil (Viagra), in Animal Models of Airways Disease. Am J Resp Crit Care Med 2004, I 69:227-234.

33. Barnett MS, Manning CD, Cieslinski LB, Burman M, Christensen SB, Torphy TJ: The ability of phosphodiesterase IV inhibitors to suppress superoxide production in guinea pig eosinophils is correlated with inhibition of phosphodiesterase IV catalytic activity. J Pharmacol Exp Ther 1995, 273:674-679.

34. Santamaria LF, Palacios JM, Beleta J: Inhibition of eotaxin-mediated human eosinophil activation and migration by the selective cyclic nucleotide phosphodiesterase type 4 inhibitor rolipram. Br J Pharmacol |997, I 2 I : | | 50- I I54.

35. Barnette MS, Bartus JO, Burman M, Christensen SB, Cieslinski LB, Esser KM, Prabhakar US, Rush JA, Torphy TJ: Association of the anti-inflammatory activity of phosphodiesterase 4 (PDE4) inhibitors with either inhibition of PDE4 catalytic activity or competition for [3H] rolipram binding. Biochem Pharmacol |996, 5 I:949-56.

36. Das AM, Flower RJ, Hellewell PG, Teixeira MM, Perretti M: A novel murine model of allergic inflammation to study the effect of dexamethasone on eosinophil recruitment. $\mathrm{Br} J$ Pharmacol 1997, I 2 1:97-104.

37. Torphy T], Barnette MS, Hay DW, Underwood DC: Phosphodiesterase IV inhibitors as therapy for eosinophil-induced lung injury in asthma. Environ Health Perspect 1994, I02(suppl I 0):79-84
38. Bradding P, Roberts JA, Britten KM, Montefort S, Djukanovic R, Mueller R, Heusser $\mathrm{CH}$, Howarth PH, Holgate ST: Interleukin-4, -5, and -6 and tumour necrosis factor-alpha in normal and asthmatic airways: evidence for the human mast cell as a source of these cytokines. Am J Respir Cell Mol Biol 1994, I 0:47I-480.

39. Cieslewicz G, Tomkinson A, Adler A, Duez C, Schwarze J, Takeda K, Larson KA, Lee JJ, Irvin C, Gelfand EW: The late, but not early, asthmatic response is dependent on IL-5 and correlates with eosinophil infiltration. J Clin Invest 1999, 104:301-308.

40. Broide DH, Lotz M, Cuomo AJ, Coburn DA, Federman EC, Wasserman SI: Cytokines in symptomatic asthma airways. J Allergy Clin Immunol 1992, 89:958-967.

41. Prabhakar U, Lipshutz D, Bartus JO, Slivjak MJ, Smith EF, Lee JC, Esser KM: Characterization of CAMP-dependent inhibition of LPSinduced TNF alpha production by rolipram, a specific phosphodiesterase IV (PDE IV) inhibitor. Int J Immunopharmacol 1994, 1 6:805-816.

42. Semmler J, Wachtel H, Endres S: The specific type IV phosphodiesterase inhibitor rolipram suppresses tumor necrosis factor-alpha production by human mononuclear cells. Int Immunopharmacol 1993, I 5:409-4I3.

43. Badger AM, Olivera DL, Esser KM: Beneficial effects of the phosphodiesterase inhibitors BRL 61063, pentoxifylline, and rolipram in a murine model of endotoxin shock. Circ Shock 1994, 44: $188-195$

44. Hatzelmann A, Schudt C: Anti-inflammatory and immunomodulatory potential of the novel PDE4 inhibitor roflumilast in vitro. J Pharmacol Exp Ther 200I, 297:267-279.

45. Takei K, Tokuyama K, Kato M, Morikawa A: Role of cyclic adenosine monophosphate in reducing superoxide anion generation in guinea pig alveolar macrophages. Pharmacol 1998 , 57:I-7.

46. Silva PMR, Alves AC, Serra MF, Lucia A, Pires A, Silva JP, Barreto EO, Corderio RSB, Jose PJ, Teixeria MM, Lagnette V, Martins MA: Modulation of eotaxin formation and eosinophil migration by selective inhibitors of phosphodiesterase type 4 isoenzyme. $\mathrm{Br}$ J Pharmacol 200I, I 34:283-294.
Publish with Bio Med Central and every scientist can read your work free of charge

"BioMed Central will be the most significant development for disseminating the results of biomedical research in our lifetime. "

Sir Paul Nurse, Cancer Research UK

Your research papers will be:

- available free of charge to the entire biomedical community

- peer reviewed and published immediately upon acceptance

- cited in PubMed and archived on PubMed Central

- yours - you keep the copyright
BioMedcentral 